\title{
An approach to reduce mapping errors in the production of landslide inventory maps
}

\author{
M. Santangelo, I. Marchesini, F. Bucci, M. Cardinali, F. Fiorucci, and F. Guzzetti \\ CNR IRPI, Via della Madonna Alta 126, 06128 Perugia, Italy \\ Correspondence to: M. Santangelo (michele.santangelo@irpi.cnr.it)
}

Received: 5 June 2015 - Published in Nat. Hazards Earth Syst. Sci. Discuss.: 1 July 2015

Accepted: 31 August 2015 - Published: 22 September 2015

\begin{abstract}
Landslide inventory maps (LIMs) show where landslides have occurred in an area, and provide information useful to different types of landslide studies, including susceptibility and hazard modelling and validation, risk assessment, erosion analyses, and to evaluate relationships between landslides and geological settings. Despite recent technological advancements, visual interpretation of aerial photographs (API) remains the most common method to prepare LIMs. In this work, we present a new semi-automatic procedure that makes use of GIS technology for the digitization of landslide data obtained through API. To test the procedure, and to compare it to a consolidated landslide mapping method, we prepared two LIMs starting from the same set of landslide API data, which were digitized (a) manually adopting a consolidated visual transfer method, and (b) adopting our new semi-automatic procedure. Results indicate that the new semi-automatic procedure (a) increases the interpreter's overall efficiency by a factor of 2, (b) reduces significantly the subjectivity introduced by the visual (manual) transfer of the landslide information to the digital database, resulting in more accurate LIMs. With the new procedure, the landslide positional error decreases with increasing landslide size, following a power-law. We expect that our work will help adopt standards for transferring landslide information from the aerial photographs to a digital landslide map, contributing to the production of accurate landslide maps.
\end{abstract}

\section{Introduction}

Landslide inventory maps (LIMs) document the type and extent of mass movements in areas ranging from single slopes, or groups of slopes (Cardinali et al., 2001), to regions (e.g. Brabb and Pampeyan, 1972; Antonini et al., 1993; Duman et al., 2005), and even entire states or nations (Delaunay, 1981; Radbruch-Hall et al., 1982; Brabb et al., 1989; Cardinali et al., 1990; Reichenbach et al., 1998; Trigila et al., 2010). LIMs are prepared using a variety of techniques and methods (Guzzetti et al., 2012), including: (i) analysis of archive and historical information (Reichenbach et al., 1998; Salvati et al., 2003), (ii) visual interpretation of stereoscopic aerial photographs (aerial photo interpretation; API) (Guzzetti and Cardinali, 1989, 1990; Cardinali et al., 1990; Brunsden, 1993; Antonini et al., 2002b; Guzzetti et al., 2002, 2012; Galli et al., 2008; Santangelo et al., 2010, 2013), (iii) visual analysis of lidar-derived images (Ardizzone et al., 2007; Van den Eeckhaut et al., 2007; Haneberg et al., 2009; Guzzetti et al., 2012; Razak et al., 2011, 2013), (iv) visual inspection of monoscopic (Marcelino et al., 2009; Gao and Maroa, 2010; Fiorucci et al., 2011; Giordan et al., 2013) and stereoscopic (Fiorucci et al., 2011; Ardizzone et al., 2013; Murillo-García et al., 2015) satellite images, and (v) image-processing techniques (Guzzetti et al., 2012) applied to lidar elevation data (Martha et al., 2010; Lu et al., 2011; Stumpf and Kerle, 2011; Van den Eeckhaut et al., 2012) and satellite imagery (Rosin and Hervás, 2005; Borghuis et al., 2007; Yang and Chen, 2010; Mondini et al., 2011a, 2013, 2014; Mondini and Chang, 2014).

Despite modern technological advancements, and the availability of new imagery, the visual interpretation of aerial photography (aerial photo interpretation; API) remains the most common method to obtain information on landslides 
(Brunsden, 1993; Guzzetti et al., 2012). In many areas, aerial photographs (APs) are the only source of landslide information in the period between the 1920s and 1973, when the images captured by the first Landsat satellite became available (McDonald and Grubbs, 1975; Sauchyn and Trench, 1978).

Production of LIMs through API is known to be a subjective and error-prone operation (Guzzetti et al., 2012; Jackson et al., 2012). The quality of the final map depends on multiple factors, including the experience and skills of the photo interpreter(s), the scale of the APs and of the base map used to prepare the inventory, and the complexity of the terrain (Carrara et al., 1992; Ardizzone et al., 2002; Galli et al., 2008; Jackson et al., 2012). A crucial - and underestimated - source of error that influences the quality of a LIM lays in the transfer of information from the original APs used to recognize demarcate the landslides, to the base map used to produce the LIM (Marchesini et al., 2013, Santangelo et al., 2015a). Most commonly, the transfer of information from the APs to the (digital or paper) map is performed visually. To the best of our knowledge, no attempt has been made to quantify the error introduced by the visual transfer of the landslide information from the APs to the base map, and to investigate technological alternatives to the visual transfer that may reduce the mapping errors, contributing to an improvement of the quality of LIMs.

We present a new semi-automatic GIS procedure for the digitization of landslides and other geomorphological information obtained through API. We test the new procedure in an area near Taormina, Sicily, where landslides are abundant. In our test area, we compare two LIMs obtained using a consolidated manual procedure for preparing the inventory and the new semi-automatic procedure, and we discuss advantages and drawbacks of the new method compared to the traditional approach.

\section{Study area and materials}

For our experiment, we selected a $93 \mathrm{~km}^{2}$ area along the NE coast of Sicily, near Taormina (Fig. 1). In the area, elevation ranges from sea level to $1187 \mathrm{~m}$, with a mean elevation of $410 \mathrm{~m}$ computed from a $2 \mathrm{~m} \times 2 \mathrm{~m}$ digital elevation model (DEM). Terrain slope ranges between 0 and $88^{\circ}$, with an average of $41^{\circ}$, and most of the slopes face towards SSW. Most of the area is drained by the Alcantara River that flows into the Ionian Sea and is characterized by a deep canyon cut into lava flows of the Etna Volcano. A W-E-trending antiformal ridge shapes the morphology of the area (APAT, 2008). Conglomerate, sandstone, and clay pertaining to the Capo D'Orlando Flysch crop out along the SE limb of the ridge. Metamorphic rocks, mainly phyllites and massive and layered carbonate rocks, crop out on the ridge top, and basalt is present in the canyon carved by the Alcantara River. The composite lithological assemblage and the complex structural setting control the morphology of the

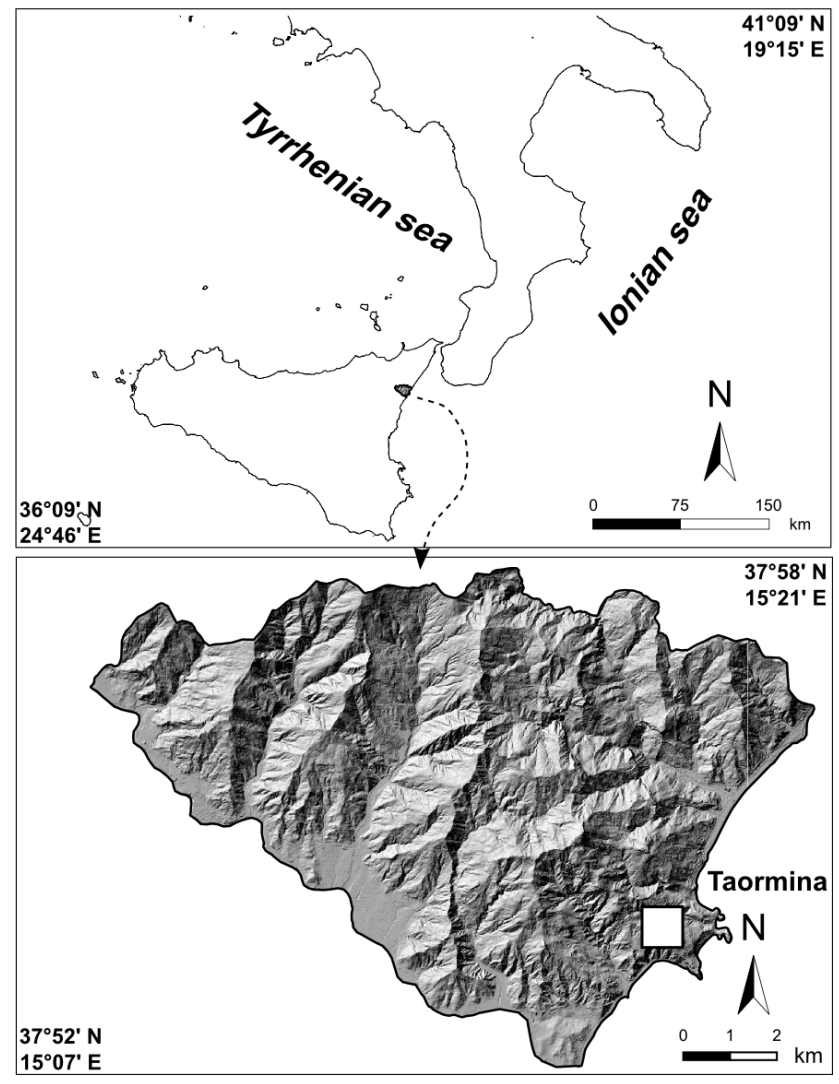

Figure 1. Location map. Shaded relief was produced from a $2 \mathrm{~m} \times 2 \mathrm{~m}$ lidar DEM.

slopes, and the location, type, abundance, and pattern of the landslides. Large, deep-seated landslides and "sackung-type" features (Di Maggio et al., 2014) are most common where metamorphic rocks crop out. Slides, earthflows, complex and composite landslides, and large debris flows are abundant where flysch rocks crop out. In places, hard rocks (carbonate, basalt) form steep, locally overhanging walls that represent the source areas of rock falls, topples, and minor rockslides.

For the study area, the following materials were available to us: (i) a topographic base map at 1:10000 scale, (ii) a $2 \times 2 \mathrm{~m}$ resolution DEM obtained from a lidar survey, (iii) a colour orthophoto map with a ground sampling distance (GSD) of $0.25 \mathrm{~m}$, and (iv) 12 black and white aerial photographs (APs) taken on 7 July 2005 at a nominal scale of $1: 28000$. The APs were $23 \mathrm{~cm} \times 23 \mathrm{~cm}$ in size, each covering an area of approximately $34 \mathrm{~km}^{2}$, and were taken using an aerial "WILD" camera with a focal length of $153.64 \mathrm{~mm}$. The side overlap between two adjacent APs is about $70 \%$, and the strip overlap about $20 \%$.

\section{Production of a landslide inventory map}

Production of a landslide inventory map (LIM) is the result of a complex process that consists of multiple steps, from 

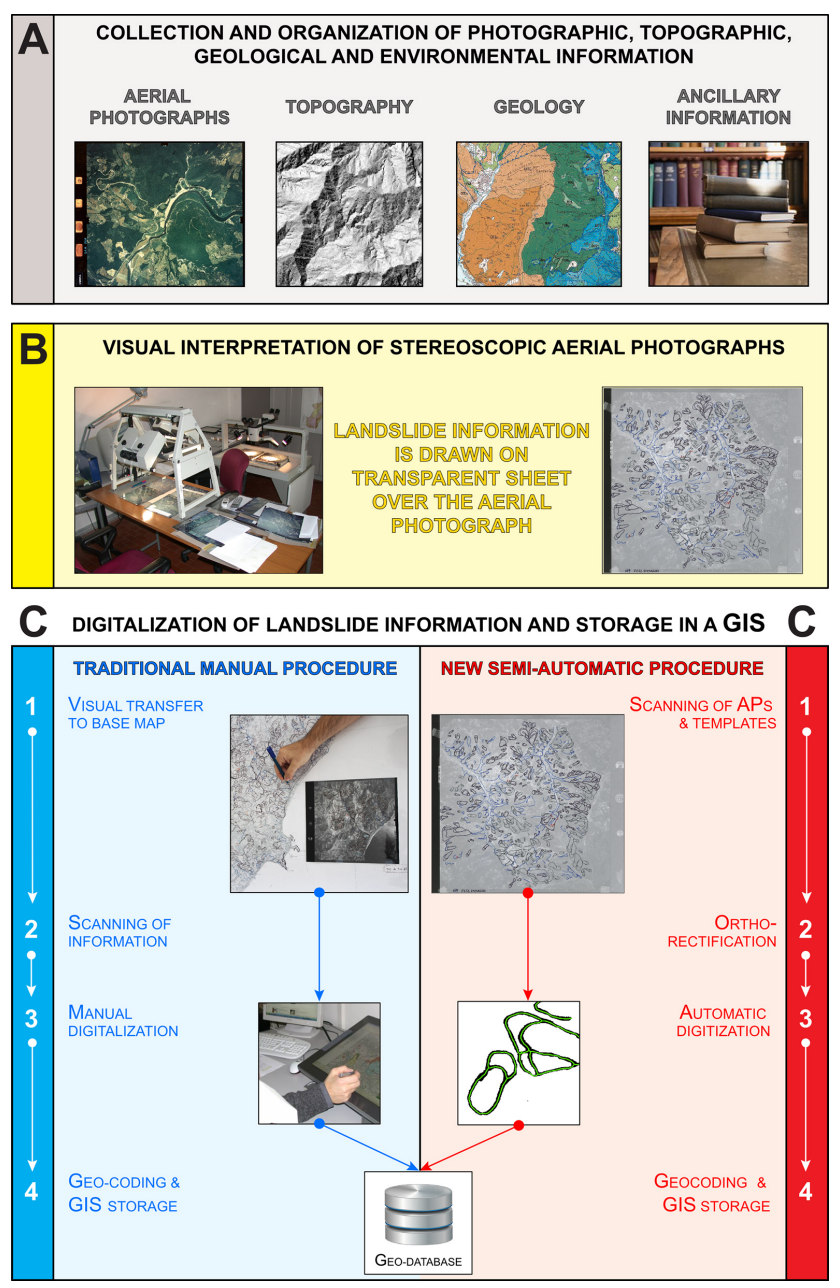

Figure 2. Description of the process of landslide mapping based on the interpretation of the aerial photographs (API). (a) Information useful to the interpretation is collected and organized. (b) Aerial photographs are interpreted using a stereoscope. Landslide and thematic information is drawn on a transparent plastic sheet (template) placed over the photographs. (c) Information is digitalized and stored in a GIS. The blue side and arrows show four steps of the consolidated (traditional) manual procedure. The red side and connectors show four steps of the new semi-automatic procedure.

the visual analysis of the stereoscopic APs using a stereoscope, to the storage of the landslide information in a GIS. Based on our experience, and the production of LIMs for more than $4 \times 10^{5} \mathrm{~km}^{2}$ in different physiographical and climatic settings in Italy (Antonini et al., 1993, 2002b; Ardizzone et al., 2012; Cardinali et al., 2001; Guzzetti and Cardinali, 1989; Santangelo et al., 2015a), and elsewhere in the world (e.g. Cardinali et al., 1990), we identify three main steps for the production of a LIM (Fig. 2).

First, (step A in Fig. 2) topographic, morphological, geological, and environmental data and information useful for the recognition of the landslides are collected and organized. Next, (step B, in Fig. 2) the available stereoscopic APs are interpreted visually (aerial photograph interpretation; API) by an interpreter - or by two interpreters when "discussion" stereoscopes are used to improve the quality of the landslide mapping (Guzzetti and Cardinali, 1990; Galli et al., 2008). In this step, the interpreter decides whether or not a feature observed in the APs is (or is not) a landslide, and determines the type (Cruden and Varnes, 1996), relative age (Santangelo et al., 2013), and estimated depth of the landslide. An expected degree of confidence in the recognition can also be attributed to each landslide, or other recognized geomorphological features (Razak et al., 2012). The interpreter draws the landslide and the additional thematic information detected on the APs on a transparent plastic sheet (template) placed over the AP using fine-scale $(0.3 \mathrm{~mm}$, or smaller) colour felt pens. Next, (step C, in Fig. 2) the information shown on the transparent plastic sheet is transferred to the base map, and stored in a GIS. This can be performed using a consolidated manual procedure, or the new semi-automatic procedure proposed in this study (Fig. 2).

\subsection{Manual procedure}

The manual procedure consists of the following four substeps (Santangelo et al., 2012; Marchesini et al., 2013). First, the information drawn on the plastic sheets placed over the APs (Fig. 3a) is transferred visually (re-drawn) to a second undeformable plastic sheet placed over the topographic base map (Fig. 3b). In this sub-step, all the topographic distortions present in the AP - the result of the conical view of the AP - are adjusted visually to match the undistorted (projected) topographic map. Second, the undistorted plastic sheet is scanned - typically using a large-scale (A0 format) scanner, imported as a raster file into a GIS, and georeferenced. Third, the landslide and the thematic information is transformed from raster to vector format (vectorization) using automatic, semi-automatic, or manual methods. Fourth, the single vector elements, each representing a landslide or a portion of a landslide (e.g. a landslide escarpment, a landslide boundary), or a morphological or geological feature (e.g. fault traces, trenches) are assembled in single or in multiple vector features. Lastly, each landslide feature is coded (labelled) with the appropriate landslide information, and stored in a GIS in single or multiple layers (Fig. 3c). When multiple layers are used, the different layers can show landslides of different types, or of different ages or periods (Santangelo et al., 2013, 2014).

Transfer of the landslide and thematic information from the AP to the base map using the manual procedure inevitably introduces errors in the LIM, including errors in the position, size, and shape of the individual landslides (Ardizzone et al., 2002; Marchesini et al., 2013). The mapping errors have different causes, including: (i) the different projections of the AP (perspective or central projection) and the topographic base map (orthographic projection), (ii) the different scales of the APs and the topographic map, (iii) a 

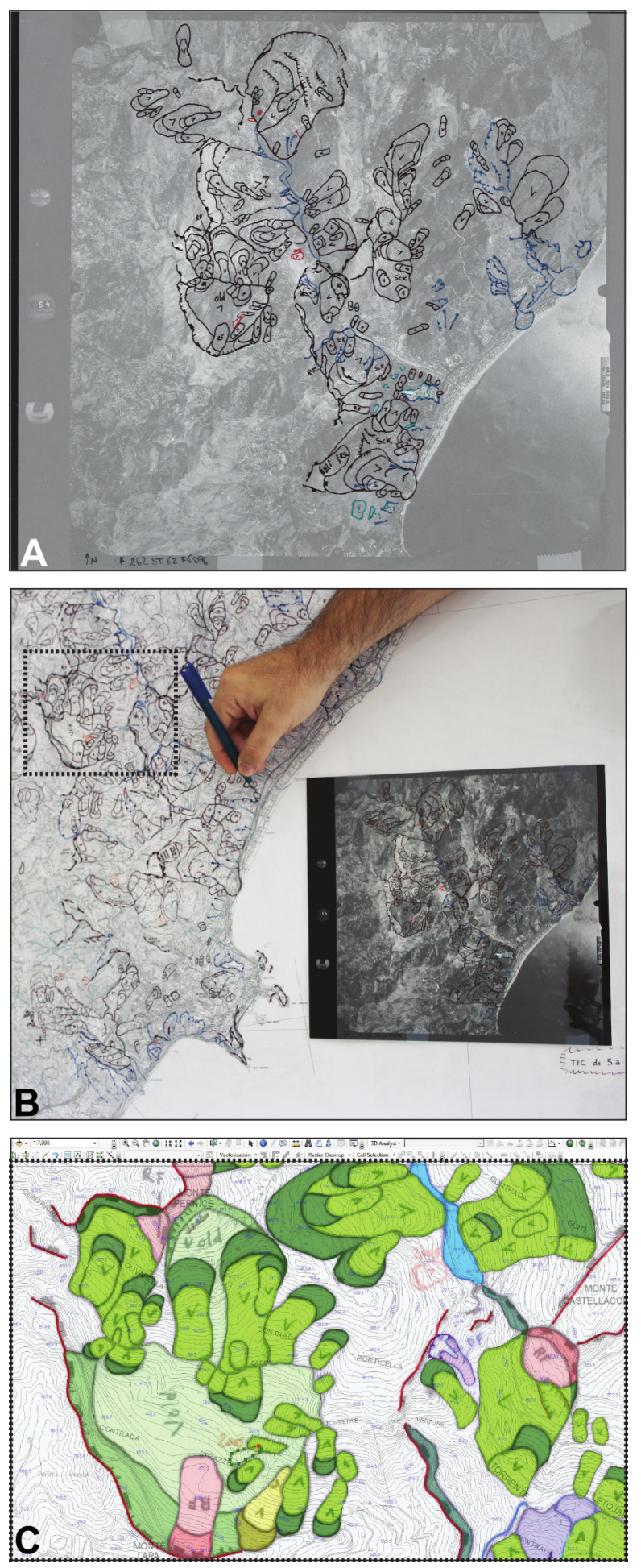

Figure 3. Main steps of the consolidated manual procedure. (a) Photo-interpreted template obtained through API. (b) Thematic information visually re-drawn on a transparent plastic sheet placed over a topographic base map. (c) Landslide information imported in the GIS, vectorized, and geocoded. smaller number of reference points on the topographic map compared to the AP, (iv) the quality of the topographic map, and (v) the complexity of the terrain. The manual method is time-consuming (Galli et al., 2008), and the quality of the LIM depends largely on the ability of the operator to transfer the mapped landslide and thematic information from the AP to the base map correctly.

\subsection{Semi-automatic procedure}

We propose a new, semi-automatic procedure to transfer the landslide and the thematic information recognized in the APs to the topographic base map. The procedure consists of the following four sub-steps (Fig. 2). First, the single AP and the associated plastic sheets showing the landslide and thematic information are scanned. Three separate scans are prepared, including: (i) a grey-tone (8-bit) image of the AP with the plastic sheet (Fig. 4a), (ii) a black and white (1-bit) image of the plastic sheet without the AP (Fig. 4b), and (iii) a colour (24-bit) image of the plastic sheet, also without the AP (Fig. 4c). The three scanned images are stored in the GRASS GIS as an imagery group in a project with Cartesian coordinates (i.e., a generic $(x, y)$ mapset). Second, the imagery group is orthorectified using the grey-tone ( $8 \mathrm{bit}$ ) scanned image of the AP and the associated plastic sheet for the interior and the exterior orientations of the AP, and of the landslide and thematic information. Third, the landslide and the thematic information shown in the scanned plastic sheet is transformed from raster to vector format, automatically. Fourth, the individual vector elements are assembled in single or in multiple vector features, each representing e.g. a landslide or a portion of a landslide, or other thematic information. Lastly, the landslide/thematic features are manually labelled with the appropriate information, and stored in the GIS in single or multiple layers (Fig. 3c). To code the individual vector features, we use the 24-bit colour image, using the colours shown in the original (colour) plastic sheet (Fig. 4c).

For our experiment, to scan the AP and the associated plastic sheets showing the landslide and the thematic information, we used an A3-format $(42.0 \mathrm{~cm} \times 29.7 \mathrm{~cm})$ Epson Expression $^{\mathrm{TM}} 10000 \mathrm{XL}$ scanner, and the SilverFast ${ }^{\circledR}$ Ai IT8 v.6.6 scanning software. The APs were scanned at a resolution of $1200 \mathrm{dpi}$, corresponding to a ground resolution of $\sim 0.6 \mathrm{~m}$ at the scale of the APs $(1: 28000)$. Considering the scales of the AP and of the topographic base map (1:10000), and the general accuracy with which landslides are detected from API, the scanning resolution was considered adequate.

For the orthorectification of the scanned images we used the "i.ortho.photo" module of GRASS GIS (GRASS development team, 2012) (Fig. 5a and b). The module requires as input data: (i) the scanned images of the AP (Fig. 4), (ii) a DEM, (iii) a georeferenced orthophoto or a detailed topographic map of the study area, and (iv) the parameters of the camera used to take the aerial photograph (Rocchini 

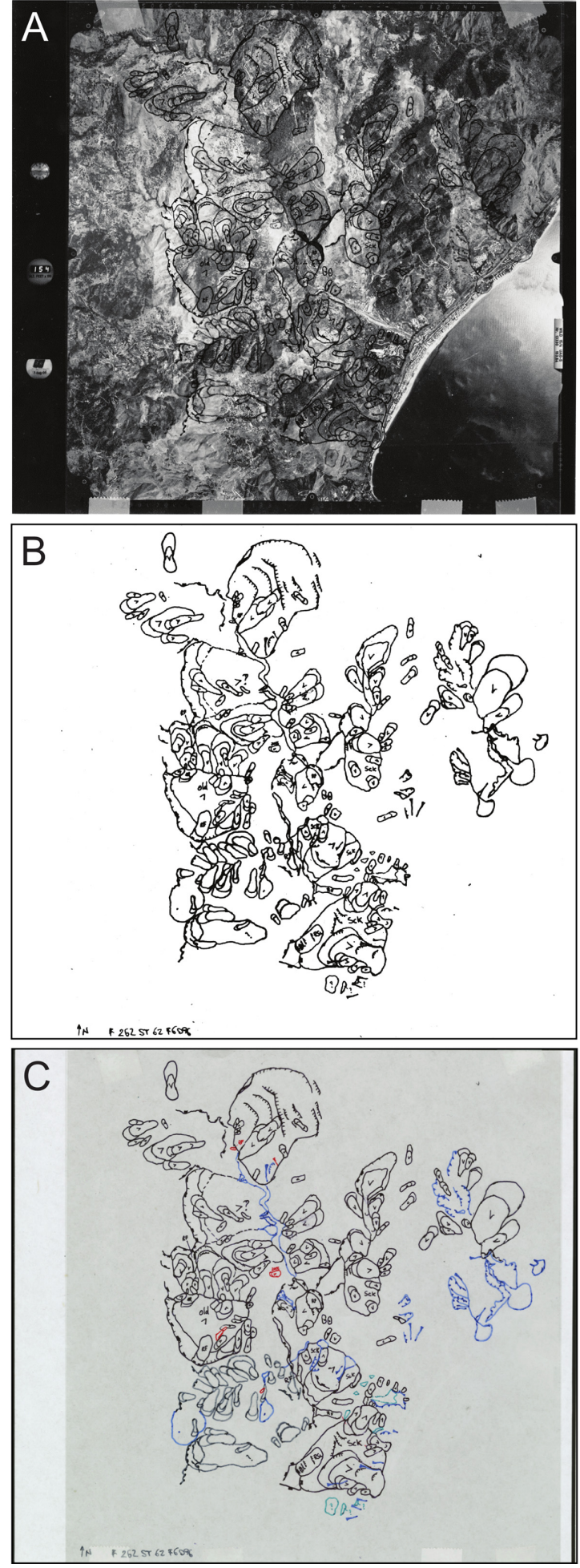

Figure 4. Input layers (scanned aerial photograph and template) required for the application of the orthorectification procedure. (a) 8bit grey-tone image of the aerial photograph and its interpreted template. (b) 1-bit black and white image of the interpreted template. (c) 24-bit colour image of the interpreted template.
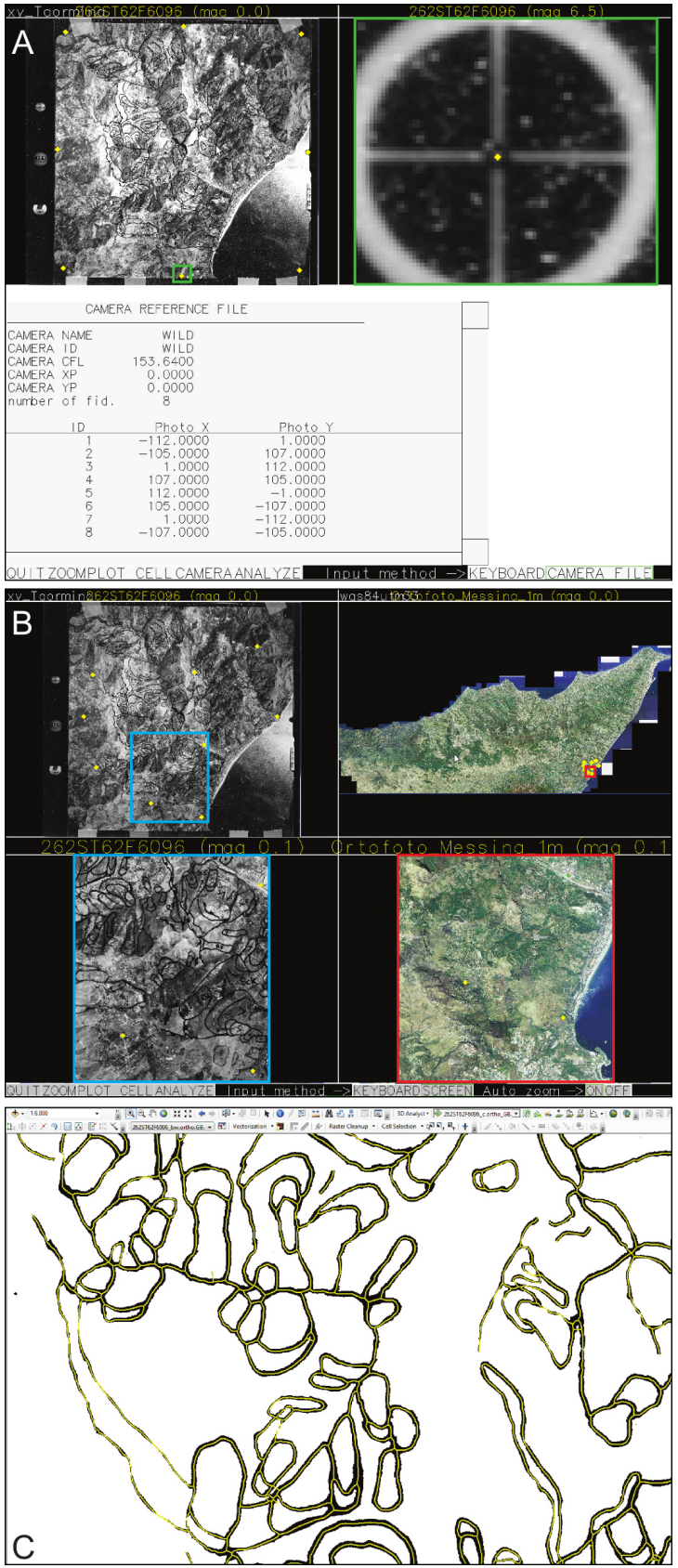

Figure 5. (a) Screenshot of the interior orientation window of the i.ortho.photo GRASS GIS tool. Left: input aerial photograph (Fig. 3a). Right: enlargement of a portion of the left image. Yellow diamonds are points chosen for the interior orientation. (b) Screenshot of the exterior orientation window of the i.ortho.photo GRASS GIS tool. Left: input aerial photograph (Fig. 3a). Right: reference orthophotograph. Yellow diamonds are points chosen for the exterior orientation. (c) Screenshot of the automatic vectorization using the ArcSCAN tool of ArcMap ${ }^{\text {TM }}$ (ArcGIS $\left.{ }^{\circledR} 10\right)$. Black lines are raster lines of the black and white orthorectified template. Green vector lines result from automatic vectorization. 

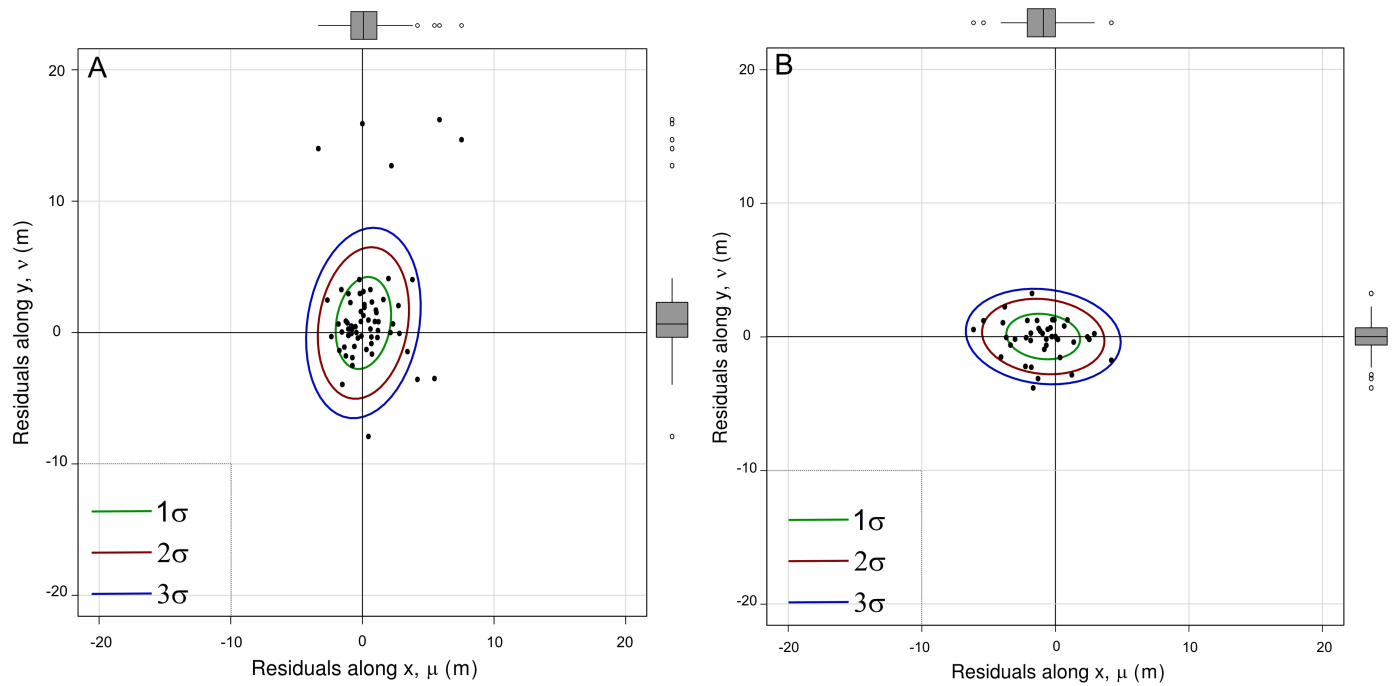

Figure 6. (a) Scatter plot of residuals along $x(\mu)$ and $y(v)$ for 63 GCPs (different from the GCPs used for the exterior orientation) achieved by orthorectification of the aerial photographs. $68 \%$ ( $1 \sigma$, green ellipse) of $\mu-v$ data points is smaller than 1.9 and $3.8 \mathrm{~m}$, respectively. $95 \%$ ( $2 \sigma$, red ellipse) of $\mu-v$ data points is smaller than 3.0 and $6.6 \mathrm{~m}$, respectively. $99 \%$ ( $3 \sigma$, blue ellipse) of $\mu-v$ data points is smaller than 4.4 and $7.8 \mathrm{~m}$, respectively. (b) Scatter plot of residuals along $x(\mu)$ and $y(v)$ showing the co-registration of the orthophotograph used for the exterior orientation of the aerial photographs, and the contour line topographic base map used for the visual transfer (Fig. $3 b$ ). For both plots, on the right and upper side of the plots, the box plots of the residuals are displayed. Data concentration ellipses of 1,2 , and $3 \sigma$ are shown. All data concentration ellipses computed giving less weight to the outliers.

et al., 2011). For the interior orientation, the coordinates of the eight fiducial marks were associated using the centre of symmetry of the AP as the origin. For the exterior orientation (Fig. 5b), the i.ortho.photo module requires that a sufficient number of ground control points (GCPs) are placed on the AP. In the literature, 16 GCPs are considered sufficient if each GCP is placed with an accuracy of $1 / 3$ of the pixel size (Bernstein, 1983; Rocchini et al., 2011), and if the GCPs cover the entire AP avoiding clustering effects. For our experiment, 16-20 GCPs were selected in each AP. Lastly, i.ortho.photo requires a number of output parameters, including the resolution (usually metres per cell/pixel width or length) of the orthorectified image and the interpolation method (e.g. nearest neighbour, bilinear, bicubic) used to resample the pixels of the scanned images to the target grid of a given coordinate reference system. The orthorectified images are exported as GeoTIFF files, for subsequent vectorization and coding of the landslide and thematic information.

For the automatic vectorization of the single orthorectified images we used the ArcScan extension of $\mathrm{ArcMap}^{\mathrm{TM}}$ (ArcGIS ${ }^{\circledR} 10$ ). The software uses a raster layer (1-bit) of the interpreted template (i.e., an orthorectified image showing the thematic information only, Fig. 5c) as input. The individual vector features (points, lines, polygons) are cleaned topologically, and then stored in shape files. The attribute table is then compiled with the appropriate landslide/thematic information using a pre-defined legend.

\subsection{Accuracy of the orthorectification}

For the rectification of APs, Rocchini et al. (2011) have shown that a robust orthorectification algorithm provides better results than rectifications techniques that do not use digital terrain information (i.e., a DEM). We adopted the algorithm described by Rocchini et al. (2011) and implemented in the i.ortho.photo module of GRASS GIS (GRASS development team, 2012). Fig. 6a shows measures of the coregistration accuracy of the APs and the orthophotograph used for the exterior orientation. For 63 GCPs (different from the GCPs used for the exterior orientation), we obtained a total root-mean-square error (RMSE) of $5 \mathrm{~m}$, and a $3 \sigma$ data concentration ellipse $<10 \mathrm{~m}$ along the $x$ axis and the $y$ axis. Considering that the graphical error for an AP at 1:28000 scale is $5.6 \mathrm{~m}$ (where the graphical error is $0.2 \mathrm{~mm} \times 28000$ ), and the (nominal) width of the felt pen used to draw the landslide information on the plastic sheets was $0.3 \mathrm{~mm}$, corresponding to $8.4 \mathrm{~m}$ at the scale of the APs, we conclude that the semi-automatic orthorectification method is suitable for the production of a LIM, at 1:10000 scale.

In Fig. 6b, we show 40 data points, out of the 63 GCPs of Fig. 6a, for which it was possible to find corresponding points on the 1:10000 scale topographic map. Those points were used to evaluate the co-registration accuracy between the topographic base map used for the visual transfer using the manual procedure, and the orthophoto used for the exterior orientation in the semi-automatic procedure. We measured a total RMSE of $2.7 \mathrm{~m}$, and a maximum RMSE of 


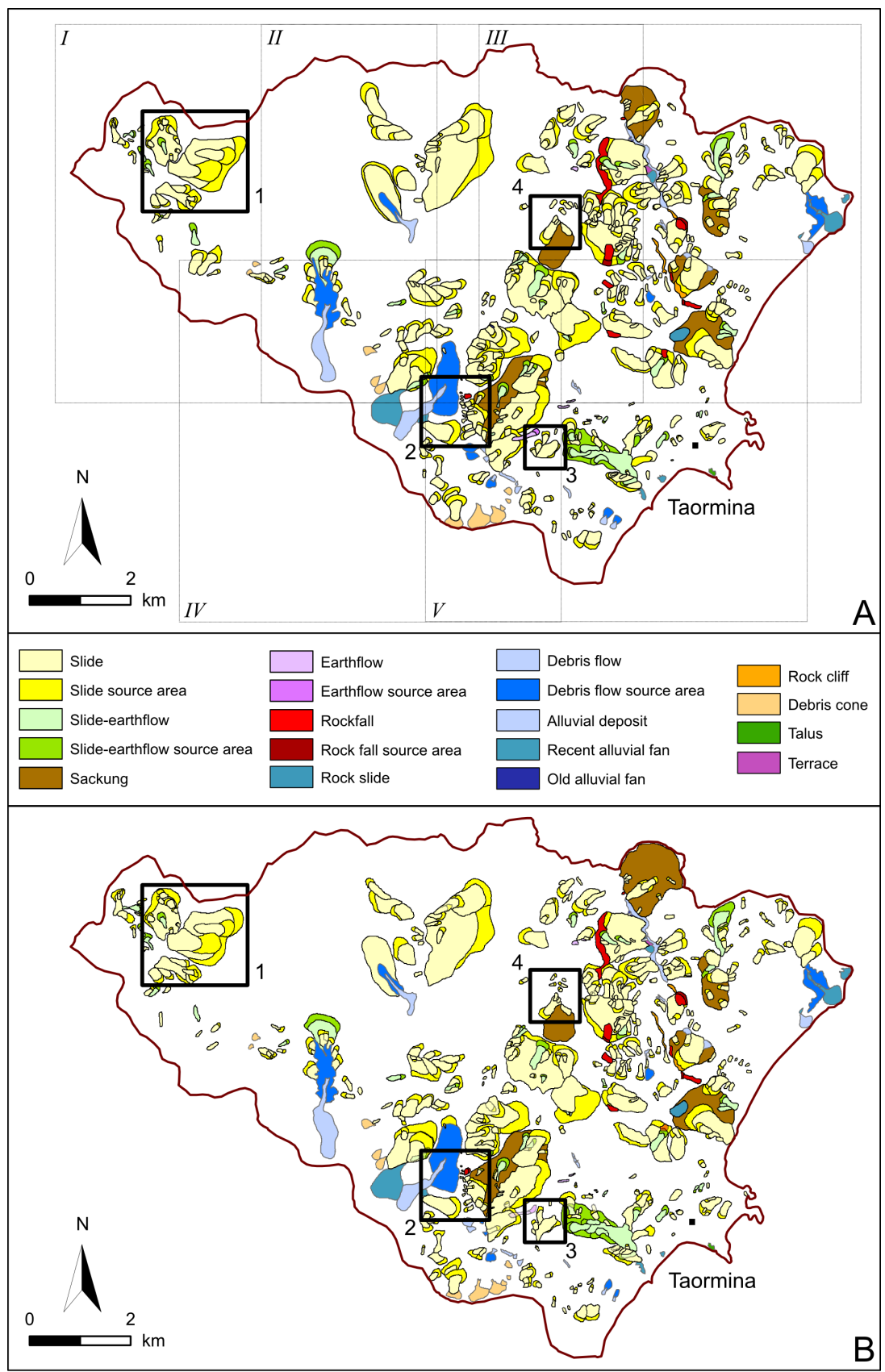

Figure 7. Landslide inventory maps (LIMs) obtained using (a) the consolidated manual procedure, and (b) the new semi-automatic procedure. Bold black boxes numbered from 1 to 4 indicate the four areas shown in Fig. 8 and named from A to D. Thin line boxes with Roman numerals show the areas covered by the five complete stereograms for which the API was carried out.

$6.2 \mathrm{~m}$, which reveal a good co-registration between the orthophotograph used for the exterior orientation of the APs, and the topographic base map used as reference for the manual procedure. The good co-registration accuracy allows for the comparison between the LIMs produced using the manual and the semi-automatic procedures.

\section{Results}

From the visual interpretation of the 12 APs (five complete stereograms) covering our study area (Fig. 7), and using the same topographic base map, we produced two LIMs. The first landslide map (map A, Fig. 7a) was prepared by adopting the traditional (consolidated) manual method to transfer the information from the APs to the base map, and in the 

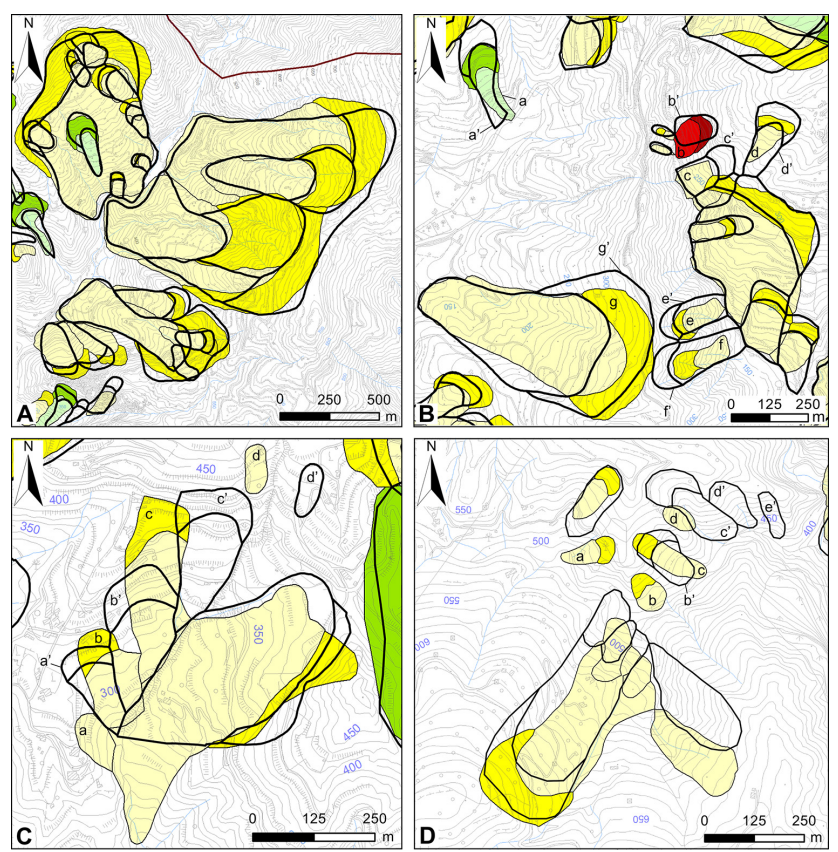

Figure 8. Visual comparison of the two inventory maps resulting from the two different procedures. Black lines are landslides mapped using the consolidated manual procedure. Coloured polygons are landslides mapped using the semi-automatic procedure. The four images (bold black boxes in Fig. 7) show situations where: (a) mapping agreement is substantially acceptable, (b) positioning of the landslides is acceptable but not the size, (c) positioning of the landslide is not acceptable, and (d) mapping agreement is very poor, and commission and omission errors occur. Lower-case letters refer to the corresponding landslides mapped using the semi-automatic and the manual (lower-case letters with apex) procedure. See text for explanation.

GIS. The second landslide map (map B, Fig. 7b) was prepared by adopting the new semi-automatic method to transfer the information from the APs to the base map, and in the GIS. Availability of two maps covering the same area and showing the same landslides allows for qualitative and quantitative comparisons of the maps. Since the differences in the two maps lay in the method used to transfer the information from the APs to the GIS, analysis of the differences allows us to evaluate the performances of the two methods, outlining advantages and limitations.

We performed an analysis of the mismatch between the inventories resulting from the manual and the semi-automatic methods. Figure 8 shows a qualitative comparison of the two LIMs in four areas (black boxes in Fig. 7) that we consider representative of different, typical mapping conditions. Visual inspection of Fig. 8a reveals an overall agreement between the two maps, with local variations dependent on the size of the landslides. In Fig. 8b, there is a good agreement in the geographical location of the single landslides, but the size of some of the landslides differs, locally significantly. Some of the mapped landslides $\left(a^{\prime}, c^{\prime}-g^{\prime}\right.$ in Fig. 8b) are larger in map A and smaller in map B, indicating a systematic overestimation of the size of the landslides when transferring the landslide information visually. Conversely, landslide $b^{\prime}$ (map A) is smaller than the corresponding landslide $b$ (map B), mapped using the semi-automatic procedure. Inspection of Fig. 8c reveals that, with a few exceptions, the size (area) of the landslides shown in the two maps is very similar, but the geographical position of some of the landslides varies significantly. In particular, the corresponding landslides $a$ and $a^{\prime}$ and $d$ and $d^{\prime}$ do not overlap. Landslides $c$ and $c^{\prime}$ and $b$ and $b^{\prime}$ overlap partially but their position does not correspond entirely. Finally, Fig. 8d shows an area where the agreement between the two maps is very poor. In this area, both the size (extent) and the geographical location of some of the landslides are affected by very large errors (e.g. landslides $b$ and $b^{\prime}, c$ and $c^{\prime}$, and $d$ and $d^{\prime}$ ). In addition, Fig. 8d shows that one landslide shown in map A (i.e., $e^{\prime}$ ) is not present in map B and, vice versa, landslide $a$ in map B is not shown in map A. Should we consider map B (prepared through the semi-automatic procedure) as the reference ("true") map, polygon $e^{\prime}$ would be considered a commission error and polygon $a$ an omission error. The differences between the two maps are the result of modifications introduced by the interpreter when transferring the information manually from the AP to the base map. The operator introduces the (rare) changes locally, in the attempt to adjust the landslide mapping to the local topographic setting shown by the base map.

Table 1 summarizes statistics of landslide area (size) for the two LIMs. The smallest landslide in map A is a slide with $A_{\mathrm{L}}=4.37 \times 10^{2} \mathrm{~m}^{2}$. The same landslide in map B has $A_{\mathrm{L}}=3.77 \times 10^{2} \mathrm{~m}^{2}$ (a difference of $60 \mathrm{~m}^{2}$ ). The smallest landslide in map B is a slide with $A_{\mathrm{L}}=1.66 \times 10^{2} \mathrm{~m}^{2}$. The corresponding landslide in map A has $A_{\mathrm{L}}=7.07 \times 10^{2} \mathrm{~m}^{2}$ (a difference of $95 \mathrm{~m}^{2}$ ). The largest landslide in map B is a sackung with $A_{\mathrm{L}}=1.87 \times 10^{6} \mathrm{~m}^{2}$. In map A, the same sackung has $A_{\mathrm{L}}=1.86 \times 10^{6} \mathrm{~m}^{2}$, revealing a difference of $10^{4} \mathrm{~m}^{2}$ $(0.5 \%)$ in size. In map A, obtained using the manual procedure, the average landslide area is $\bar{A}_{\mathrm{L}}=7.48 \times 10^{4} \mathrm{~m}^{2}$, and in map $\mathrm{B}$, obtained by carrying out the semi-automatic procedure, the average landslide area is $\bar{A}_{\mathrm{L}}=7.40 \times 10^{4} \mathrm{~m}^{2}$. This is a reduction of $1.1 \%$ of the average landslide area. The total landslide area is $A_{\mathrm{LT}}=3.74 \times 10^{7} \mathrm{~m}^{2}$ for map A, and $A_{\mathrm{LT}}=3.57 \times 10^{7} \mathrm{~m}^{2}$ for map B. The reduction in the total landslide area, $1.7 \times 10^{6} \mathrm{~m}^{2}$, is not small $(4.5 \%)$ and conditions the percentage of landslide area (landslide density), which is $39.1 \%$ for map A (manual procedure) and $38.4 \%$ for map B (semi-automatic procedure).

The probability (or frequency) of landslide area $A_{\mathrm{L}}$ is known to obey a typical probability distribution (Stark and Hovius, 2001; Guzzetti et al., 2002; Malamud et al., 2004a). For small landslides, the probability of landslide area $p\left(A_{\mathrm{L}}\right)$ increases with landslide area $A_{\mathrm{L}}$ up to a maximum value (the "rollover") after which $p\left(A_{\mathrm{L}}\right)$ decreases rapidly following a power-law. The empirical $p\left(A_{\mathrm{L}}\right)$ is reasonably well ap- 
Table 1. Comparison of descriptive statistics of landslide area for the landslide inventories obtained following the traditional manual procedure and the new semi-automatic procedure for transferring landslide information from the aerial photograph to the topographic base map. $N_{\mathrm{LT}}$ is the number and $A_{\mathrm{LT}}$ is the area of landslides mapped using the manual method (map A). $N_{\mathrm{LO}}$ is the number, and $A_{\mathrm{LO}}$ is the area of landslides mapped using the semi-automatic method (orthorectification). $\mathrm{L}_{N}$ is the number of landslides. $A_{\mathrm{MIN}}, A_{\mathrm{MAX}}, A_{\mathrm{AVG}}, A_{\mathrm{TOT}}$ are the minimum, maximum, average, and total landslide area.

\begin{tabular}{|c|c|c|c|c|c|c|c|c|c|c|}
\hline \multirow[t]{2}{*}{ Landslide type } & \multicolumn{2}{|c|}{$L_{\mathrm{N}}(\#)$} & \multicolumn{2}{|c|}{$A_{\mathrm{MIN}}\left(\mathrm{m}^{2}\right)$} & \multicolumn{2}{|c|}{$A_{\mathrm{MAX}}\left(\mathrm{m}^{2}\right)$} & \multicolumn{2}{|c|}{$A_{\mathrm{AVG}}\left(\mathrm{m}^{2}\right)$} & \multicolumn{2}{|c|}{$A_{\text {TOT }}\left(\mathrm{m}^{2}\right)$} \\
\hline & $N_{\mathrm{LO}}$ & $N_{\mathrm{LT}}$ & $A_{\mathrm{LO}}$ & $A_{\mathrm{LT}}$ & $A_{\mathrm{LO}}$ & $A_{\mathrm{LT}}$ & $A_{\mathrm{LO}}$ & $A_{\mathrm{LT}}$ & $A_{\mathrm{LO}}$ & $A_{\mathrm{LT}}$ \\
\hline Slide & 390 & 391 & $1.66 \times 10^{2}$ & $4.37 \times 10^{2}$ & $1.80 \times 10^{6}$ & $1.84 \times 10^{6}$ & $6.44 \times 10^{4}$ & $6.73 \times 10^{4}$ & $2.51 \times 10^{7}$ & $2.63 \times 10^{7}$ \\
\hline Earthflow & 5 & 5 & $2.92 \times 10^{3}$ & $2.62 \times 10^{3}$ & $4.03 \times 10^{4}$ & $3.64 \times 10^{4}$ & $1.24 \times 10^{4}$ & $1.24 \times 10^{4}$ & $6.19 \times 10^{4}$ & $6.20 \times 10^{4}$ \\
\hline Slide-earthflow & 47 & 48 & $1.86 \times 10^{3}$ & $2.87 \times 10^{3}$ & $7.26 \times 10^{5}$ & $2.15 \times 10^{5}$ & $5.52 \times 10^{4}$ & $5.56 \times 10^{4}$ & $2.59 \times 10^{6}$ & $2.67 \times 10^{6}$ \\
\hline Sackung & 6 & 6 & $3.48 \times 10^{5}$ & $3.71 \times 10^{5}$ & $1.2 \times 10^{6}$ & $0.57 \times 10^{6}$ & $8.83 \times 10^{5}$ & $7.77 \times 10^{5}$ & $5.30 \times 10^{6}$ & $4.66 \times 10^{6}$ \\
\hline Rock-slide & 1 & 1 & $7.12 \times 10^{4}$ & $7.61 \times 10^{4}$ & $7.12 \times 10^{4}$ & $7.61 \times 10^{4}$ & $7.13 \times 10^{4}$ & $7.61 \times 10^{4}$ & $7.13 \times 10^{4}$ & $7.61 \times 10^{4}$ \\
\hline Debris flow & 23 & 24 & $9.19 \times 10^{2}$ & $8.09 \times 10^{2}$ & $8.26 \times 10^{5}$ & $8.63 \times 10^{5}$ & $9.55 \times 10^{4}$ & $9.19 \times 10^{4}$ & $2.19 \times 10^{6}$ & $2.21 \times 10^{6}$ \\
\hline Rockfall & 10 & 10 & $2.49 \times 10^{3}$ & $3.54 \times 10^{3}$ & $1.42 \times 10^{5}$ & $1.53 \times 10^{5}$ & $3.64 \times 10^{4}$ & $3.78 \times 10^{4}$ & $3.64 \times 10^{5}$ & $3.78 \times 10^{5}$ \\
\hline Soil slide & - & 1 & - & $2.84 \times 10^{3}$ & - & $2.84 \times 10^{3}$ & - & $2.84 \times 10^{3}$ & - & $2.84 \times 10^{3}$ \\
\hline All landslides & 482 & 486 & $1.66 \times 10^{2}$ & $4.37 \times 10^{2}$ & $1.87 \times 10^{6}$ & $1.86 \times 10^{6}$ & $7.40 \times 10^{4}$ & $7.48 \times 10^{4}$ & $3.57 \times 10^{7}$ & $3.64 \times 10^{7}$ \\
\hline
\end{tabular}
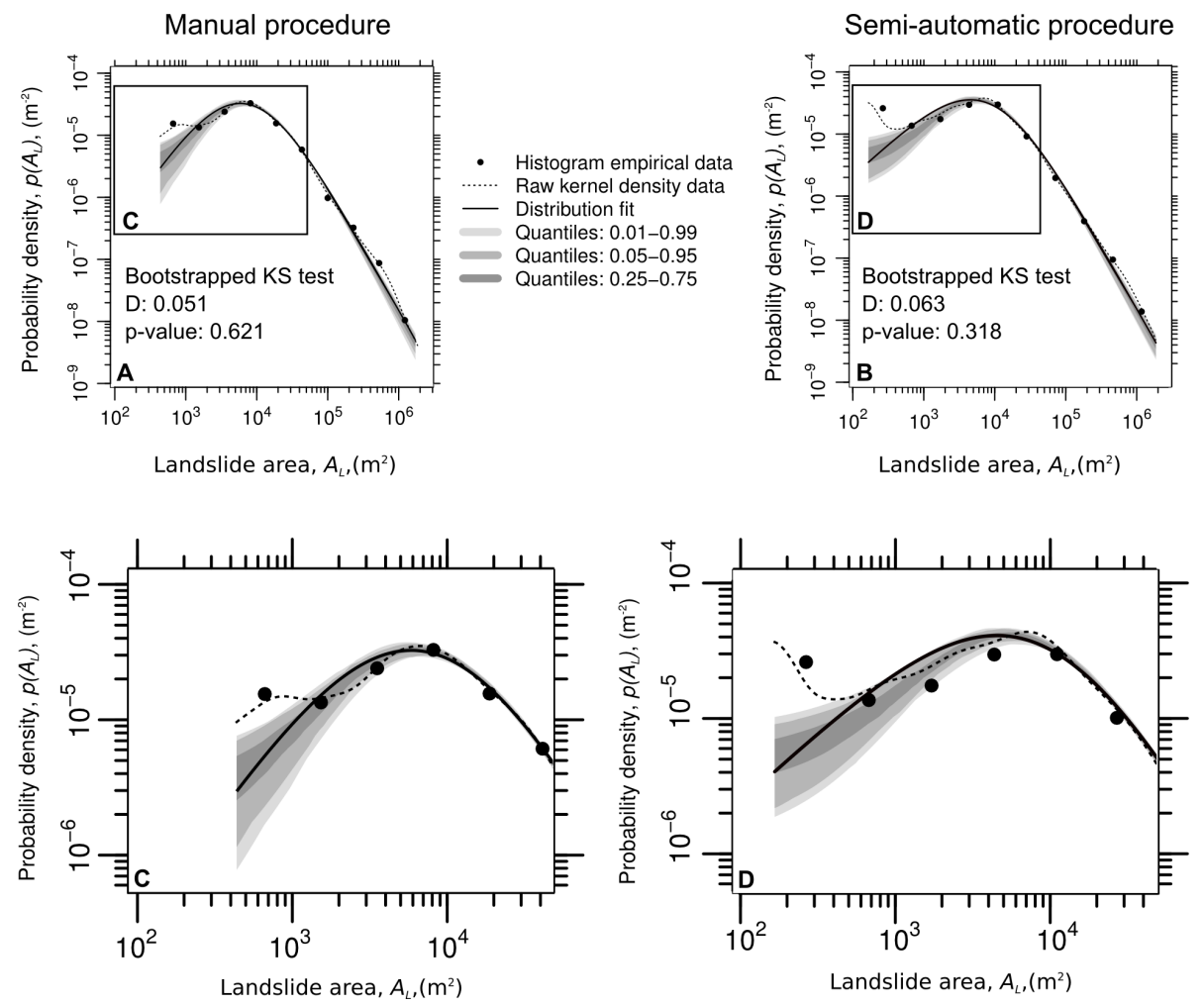

Figure 9. Comparison of the inverse-gamma (Malamud et al., 2004a) probability density function (pdf) computed for map A and map B. (a) pdf of the inventory obtained by the manual method (map A). (b) pdf of the inventory obtained by the orthorectification method (map B). (c) Enlargement of (a), and (d) enlargement of (b) are provided for aiding visual comparison of the two distributions.

proximated by the double-Pareto (Stark and Hovius, 2001) or the inverse-gamma (Malamud et al., 2004a) functions. Using specific software (Rossi et al., 2009) we determined $p\left(A_{\mathrm{L}}\right)$ for the two inventories. Results are shown in Fig. 9a, $\mathrm{c}$ and $\mathrm{b}$, and $\mathrm{d}$ that portray the inverse-gamma approximation to $p\left(A_{\mathrm{L}}\right)$ for map A (manual method) and map B (semiautomatic method), respectively. Comparison of Fig. 9a, c and $\mathrm{b}$, and $\mathrm{d}$ reveals that despite a slight difference in the slope of the power-law scaling ( $\alpha=2.06$ for map A and $\alpha=2.02$ for map B; Table 2), the two distributions are in good agreement for $A_{\mathrm{L}}>1 \times 10^{3} \mathrm{~m}^{2}$, and are somewhat different only for small landslides $\left(A_{\mathrm{L}}<1 \times 10^{3} \mathrm{~m}^{2}\right)$. Table 2 shows that the rollover for map $\mathrm{A}\left(A_{\mathrm{L}}=6.40 \times 10^{3} \mathrm{~m}^{2}\right)$ is slightly larger than for map B $\left(A_{\mathrm{L}}=5.33 \times 10^{3} \mathrm{~m}^{2}\right)$. 
Table 2. Comparison of scaling exponent (alpha) and rollover (size of the most abundant landslide) for the probability distribution functions computed for map A (manual method) and map B (semiautomatic method). Best fits computed through maximum likelihood estimation.

\begin{tabular}{lrr}
\hline & $\alpha+1$ & Rollover $\left(\mathrm{m}^{2}\right)$ \\
\hline Map A & 2.064 & 6397 \\
Map B & 2.020 & 5326 \\
\hline
\end{tabular}

We obtained an additional quantitative analysis of the differences between the two inventories modifying the mapping error index $E$ proposed by Carrara et al. (1992), and used e.g. by Ardizzone et al. (2002) and by Galli et al. (2008). The innovation of our work was to calculate the positioning error index $E_{i}$ for each pair of corresponding landslides in the two inventories:

$E_{i}=\frac{\left(A_{i} \cup B_{i}\right)-\left(A_{i} \cap B_{i}\right)}{\left(A_{i} \cup B_{i}\right)}$,

where $A_{i}$ is a landslide in map $\mathrm{A}$ and $B_{i}$ is the corresponding landslide in map $\mathrm{B}$, and $\left(A_{i} \cup B_{i}\right)$ and $\left(A_{i} \cap B_{i}\right)$ are the geometrical union and the geometrical intersection of the two corresponding landslides, respectively. This is different from what was proposed by Carrara et al. (1992) who summed the areas of all the landslides in map A and map B to calculate their mapping error index $E$.

We identified 482 pairs of corresponding landslides for which we calculated the positioning error $E_{i}$, with values in the range of 0.05 to 1.00 . The average value for the positioning error $E_{i}$ was 0.44 , and the median of the error was 0.41 (dashed line in Fig. 10). We compare these figures to the mapping error $E=0.19$, computed using the method proposed by Carrara et al. (1992). In Fig. 10, for each pair of corresponding landslides, we plot the value of $E_{i}$ against the area $A_{\mathrm{L}}$ of the landslide shown in map A (produced using the manual method). Inspection of the plot reveals that the positioning error $E_{i}$ is largest for the very small landslides and (with a few exceptions) decreases rapidly with increasing landslide area. For slope failures with $A_{\mathrm{L}}<1 \times 10^{5} \mathrm{~m}^{2}$, the positioning error $E_{i}$ exhibits a large variability. For landslides with $A_{\mathrm{L}}>1 \times 10^{5} \mathrm{~m}^{2}$ the positioning error $E_{i}$ is generally smaller than 0.3 , and does not exceed 0.1 for landslides with $A_{\mathrm{L}}>4.2 \times 10^{5} \mathrm{~m}^{2}$.

Figure 10 shows that large positioning errors are associated to small landslides. When analysing stereoscopic APs visually, small landslides are identified based primarily on their photographic evidence (tone, mottling, pattern, texture) in the photographs, and not based on their morphological characteristics (the presence, association, and pattern of e.g. concavities, convexities, escarpments, back-slopes), which can be very subtle. However, this photographic information is typically not shown in the topographic maps, making it difficult for the interpreter to locate and map the small land-

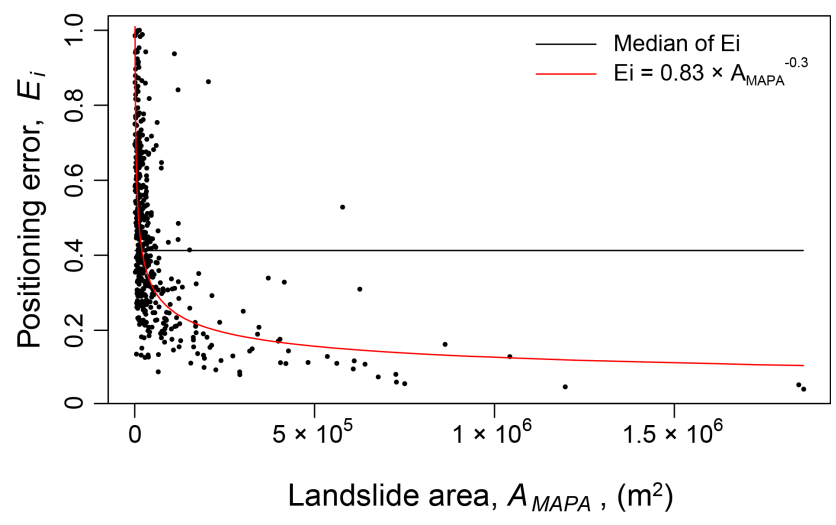

Figure 10. Scatter plot of the positioning error index $\left(E_{i}\right)$ against the landslide area, mapped using the traditional procedure ( $\left.A_{\text {MAPA }}\right)$. The plot shows a heavy-tailed distribution of $E_{i}$ that decays with increasing landslide area, following a power-law (red line). Both axes are in linear scale. The median value of $E_{i}(0.41)$ is displayed by a black line.

slides in the base map accurately. In other words, when the interpreter transfers small landslides from the AP to the base map visually, he/she uses a subset of the information available for the detection of the landslide in the AP. Lack of information contributed to the mapping error. Conversely, large landslides typically exhibit a distinct morphological signature (Pike, 1988) that is shown (partially or totally) in the topographic maps, making it simpler for the interpreter to transfer the landslide information to the base map accurately. This reduces the mapping error for large and very large landslides. The same applies to channelled debris flows that occur primarily along channels visible on the topographic maps, and deposit the failed material on debris fans that are also visible on the topographic maps.

\section{Discussion}

We tested a new semi-automatic procedure to transfer landslide and other geomorphological information captured through API from the original aerial photographs to a digital landslide database in a GIS environment. The new procedure can contribute to the efficient production of accurate LIMs and geomorphological maps over large areas. Considering the entire landslide mapping process exemplified in Fig. 2, the semi-automatic procedure reduces significantly (or avoids completely) the subjectivity introduced by the visual (manual) transfer of the landslide and geomorphological information from the APs to the digital database. This reduces mapping errors, enhancing the quality of a LIM.

In our study area, map B obtained adopting the new semiautomatic procedure, shows landslides located more accurately than the corresponding landslides in map A, produced by the traditional manual method. Although "ground truth" i.e., the "true" location, size, and shape of the landslides is 
Table 3. Comparison of the time necessary for the entire landslide mapping process (Fig. 2) using the different methods described in the text. Time is given in hours per one complete stereogram, per person. API, Aerial Photo Interpretation. A: visual analysis of the aerial photograph; B: mapping of the landslide information on the aerial photograph; C: visual, manual transfer of the landslide information; D: orthorectification; E: manual vectorization of the scanned landslide information; F: automatic vectorization of the landslide information; G: vector editing; and $\mathrm{H}$ : geocoding and database editing.

\begin{tabular}{|c|c|c|c|c|c|c|c|c|c|}
\hline & & \multicolumn{8}{|c|}{ Time required for landslide mapping (h) } \\
\hline & & \multicolumn{2}{|c|}{ API } & \multicolumn{2}{|c|}{ Transfer } & \multicolumn{3}{|c|}{ Vectorization } & \multirow{2}{*}{$\frac{\text { Geo-coding }}{\mathrm{H}}$} \\
\hline & & A & B & $\mathrm{C}$ & $\mathrm{D}$ & $\mathrm{E}$ & $\mathrm{F}$ & G & \\
\hline \multirow{5}{*}{$\begin{array}{l}\text { Time } \\
\text { (h) }\end{array}$} & Min & 0.5 & 2.5 & 2 & 0.5 & 1 & 0.5 & 0.5 & 2 \\
\hline & $\operatorname{Max}$ & 1 & 7 & 10 & 1 & 5 & 1 & 1 & 7 \\
\hline & & \multicolumn{8}{|c|}{ Total time required for the preparation of a landslide database in a GIS (h) } \\
\hline & & \multicolumn{4}{|c|}{ Transfer and vectorization } & \multicolumn{4}{|c|}{ Mapping } \\
\hline & & \multicolumn{2}{|c|}{$\begin{array}{c}\text { Manual } \\
\mathrm{C}+\mathrm{E}\end{array}$} & \multicolumn{2}{|c|}{$\begin{array}{c}\text { Semi-automatic } \\
\mathrm{D}+\mathrm{F}\end{array}$} & & $\begin{array}{l}\text { anual } \\
+\mathrm{E}+\mathrm{G}+\mathrm{H}\end{array}$ & \multicolumn{2}{|c|}{$\begin{array}{c}\text { Semi-automatic } \\
\mathrm{A}+\mathrm{B}+\mathrm{D}+\mathrm{F}+\mathrm{G}+\mathrm{H}\end{array}$} \\
\hline \multirow{2}{*}{$\begin{array}{l}\text { Time } \\
\text { (h) }\end{array}$} & Min & \multirow{2}{*}{\multicolumn{2}{|c|}{$\begin{array}{c}3 \\
15\end{array}$}} & \multirow{2}{*}{\multicolumn{2}{|c|}{$\begin{array}{l}1 \\
2\end{array}$}} & & 8.5 & \multirow{2}{*}{\multicolumn{2}{|c|}{$\begin{array}{c}6.5 \\
18\end{array}$}} \\
\hline & Max & & & & & & 31 & & \\
\hline
\end{tabular}

not available to us (as is rarely the case in landslide mapping, Santangelo et al., 2010), and being aware of the RMSE of $7.7 \mathrm{~m}$ introduced by the orthorectification of the APs in map B (C2 in Fig. 2), we consider map B as reasonably "correct" in terms of the geographical location, size, and shape of the mapped landslides. As a consequence, we interpret the observed differences (mismatches) in map A as errors introduced by the visual transfer of the landslide information in the manual procedure ( $\mathrm{Cl}$ in Fig. 2).

We measured the overall degree of mismatching between the two inventories (map A vs. map B) using the error index $E$ (Eq. 1) introduced by Carrara et al. (1992), and obtained a value for the mapping error index $E=0.19$. This suggests that overall, the two maps are rather similar (Ardizzone et al., 2002). Visual inspection of Fig. 7 confirms the impression. However, inspection of Fig. 8 reveals a number of (small and large) local differences between single landslide pairs in the two inventories. To quantify the individual differences, we calculated the positional error $E_{i}$ for 482 pairs of corresponding landslides in the two inventories. The result revealed positional errors in the range $0.05 \leq E_{i} \leq 1.00$, with an average error $\overline{E_{i}}=0.44$. The difference with $E=0.19$ is significant, and suggests that the lumped measure provided by the mapping error index $E$ of Carrara et al. (1992) overestimates the degree of geographical matching (and underestimates the mismatch) between the two maps.

Our results also revealed that the positional error of single landslides $E_{i}$ depends on the size $A_{\mathrm{L}}$ of the landslides, with small landslides exhibiting a larger positional error than larger landslides (Fig. 10). Interestingly, the dependence of the positional error on landslide area is well approximated by a power-law, $E_{i}=8.03 \times A_{\mathrm{L}}^{-0.3}$. This information can be used to estimate the expected positional error of single land- slides in LIMs produced manually. We maintain that this is important (and new) information for the users of a LIM.

Time is a critical aspect in the production of LIMs. For a LIM covering a large or very large area (thousands of square kilometres) the production of an accurate inventory map can take several months to a few years (Galli et al., 2008; Guzzetti et al., 2012). A significant part of the time used to prepare a LIM is spent in transferring the landslide information from the APs to the digital landslide database. The new semi-automatic procedure reduces the time (and hence the cost) for the production of a LIM significantly.

Table 3 shows a comparison of the time used to prepare our two inventories, using the traditional mapping procedure and adopting the new semi-automatic procedure. In the Table, time is given in hours per one pair of stereoscopic APs (one stereogram), per person. Considering that we analysed five stereograms to prepare the two inventories, in the Table we list the minimum and the maximum time required to complete the mapping of a stereogram. The time required for the API varied significantly, depending on the complexity of the terrain. It was minimum in geomorphologically "simple" areas, where terrain and environmental setting were homogenous, and where landslides were rare or simple to identify and map. The time increased with increasing terrain complexity and local setting, where landslides were abundant, and where multiple generations of landslides were present. The time required for the visual transfer of the information from the APs to the digital database depended also on the complexity of the terrain, and on the complexity and quantity of the landslide information drawn on the APs. The time for the orthorectification of the scanned APs depended largely on the difficulty of identifying adequate GCPs on the images used for the exterior orientation. The operation was simple 
(and fast) in urban areas, and difficult (and time-consuming) in rural or forested areas where adequate GCPs were difficult to identify. The time required for all geo-coding operations depended on the quantity of the landslides and the other geomorphological features, and on their geographical and topological relationships.

Comparison of the time required for transferring the landslide information from the APs to the GIS database (without geo-coding) reveals that the new procedure (and specifically the orthorectification step) accelerated the process by a factor of 4-10, compared to the visual (manual) transfer. If geocoding is considered, the acceleration factor is in the range of 3 to 8 (Table 3). The improvement is significant, and measures the gain in efficiency introduced by the semi-automatic procedure. When the entire mapping workflow is considered (Fig. 2) the gain in efficiency is somewhat lower, but remains significant. The difference (gain) in time for one person to complete the mapping of one stereogram ranged from a minimum of $2 \mathrm{~h}$ to a maximum of $13 \mathrm{~h}$. These figures suggest that the new semi-automatic procedure is always more convenient (more efficient) than the traditional (manual) procedure, with the efficiency increasing where the geomorphological complexity of the area increases.

In our experiment, the API phase took a total of $31.5 \mathrm{~h}$. Orthorectification of the APs took $4.5 \mathrm{~h}$. This compares to $35 \mathrm{~h}$ required for the visual transfer of the information with the manual procedure. Automatic vectorization took $4.5 \mathrm{~h}$, which compares to the $22 \mathrm{~h}$ for the manual vectorization. Geo-coding required the same amount of time for both procedures $(32 \mathrm{~h})$. Overall, using the new semi-automatic procedure the time needed to complete the landslide inventory (map B) was $40.5 \mathrm{~h}$, which is $44 \%$ of the time ( $92.5 \mathrm{~h}$ ) used to prepare the inventory adopting the traditional mapping procedure (map A). Including the API phase, the time used to cover an area of $93 \mathrm{~km}^{2}$ with a detailed (1:10000 scale) geomorphological LIM (Guzzetti et al., 2012) was $72 \mathrm{~h}$ (nine working days) using the semi-automatic procedure, and was $124 \mathrm{~h}$ (15.5 working days) using the manual procedure. In other words, the new procedure increased the interpreter's productivity from 0.32 to 0.55 stereograms per person per day, a $72 \%$ increase. For completing the landslide mapping of one stereogram, a geomorphologist needs 2 days using the new semi-automatic procedure, and 3 days using the traditional manual procedure. We acknowledge that these figures are estimates, and subjected to variations depending on the local geological, morphological and land use settings, on the quality of the topographic base map, on the number and complexity of the landslides and on their geometrical and topological relationships.

Despite the clear gain in mapping accuracy and efficiency, the new semi-automatic procedure is not free of problems, and care is needed when using the procedure to prepare a LIM. A number of factors influence the geographical accuracy of the landslides shown in a LIM produced by carrying out the semi-automatic procedure, including the accuracy of the DEM, of the interior orientation, and of the GCPs used for the exterior orientation. Selection of the GCPs for the exterior orientation is a crucial, and the most delicate step of the procedure. Accuracy of this step depends on the geographical accuracy and resolution of the base map, and on the difference in age between the base map and the aerial photographs that need to be orthorectified. In our study, the aerial photographs were taken in 2005, and the orthophotograph (base map) used to select the GCPs was taken in 2007 with a resolution of $0.25 \mathrm{~m}$. This made it simple to identify the GCPs accurately. In other areas, accurate selection of a sufficient number of GCPs may be problematic, limiting the quality of the orthorectified image.

Figure 6 shows that the geographical co-registration between the orthorectified aerial photographs and the orthophotograph (base map) used for the exterior orientation is not perfect, and that it is slightly worse along the N-S direction than along the E-W direction. When a LIM is shown on a base map different from the map used for the orthorectification, the differences (including co-registration errors) between the two base maps combine, contributing to degrading the location accuracy of the landslides shown in the new base map. In our study, the co-registration accuracy plots portrayed in Fig. $6 a$ and $b$ show that $95 \%$ of the overall co-registration errors are within a range of $9.0 \mathrm{~m}$ along the $x$ axis (E-W direction), and $10.1 \mathrm{~m}$ along the $y$ axis $(\mathrm{N}-\mathrm{S}$ direction). The sum of the total RMSEs for the two base maps (i.e. the RMSE obtained between the orthorectified APs and the orthophotograph, and the RMSE obtained between the orthophotograph and the topographic map) is $7.7 \mathrm{~m}$. We consider this is an acceptable error for a 1:10000 scale LIM ( $\sim 0.8 \mathrm{~mm}$ on the map).

LIMs are used for many purposes, and their quality affects the results of the investigations performed using the LIMs. This is seldom considered by the investigators (Guzzetti et al., 2012). Supervised remote sensing image classification techniques for the detection and mapping of landslides use LIMs in their training phase, and validate the mapping against independent information (Cheng et al., 2004; Nichol et al., 2006; Borghuis et al., 2007; Yang and Chen, 2010; Lu et al., 2011; Mondini et al., 2011b; Stumpf and Kerle, 2011; Guzzetti et al., 2012). Training performed using LIMs produced using the manual method can affect the ability of the image classifiers to detect and map the landslides negatively. For validation purposes, independent landslide information captured through API is often considered "correct" (Congalton, 1991) i.e., the "ground truth". Our work demonstrates that (in our study area, but we maintain the same occurs in many other areas) this is not the case, even assuming a hypothetical "error-free" API phase. Our results suggest that for training and validation of remote sensing image classifications, LIMs produced through robust orthorectification of APs (i.e., using the semi-automatic procedure) provide more accurate results than those obtained using manually prepared LIMs. 
Temporal statistics of landslides used e.g. to ascertain landslide hazard (Guzzetti et al., 2005, 2006) or risk (Cardinali et al., 2002; Reichenbach et al., 2004), and to determine landslide erosion or mobilization rates (Guzzetti et al., 2009; Fiorucci et al., 2011), are extracted from multi-temporal or seasonal landslide maps. The accuracy of the temporal calculations depend on the accuracy of the multi-temporal or seasonal maps. Misplaced landslides can result in an overestimation or underestimation of the temporal frequency of landslides in an area (Fig. 7c), introducing errors affecting hazard and risk assessments, and erosion studies. Landslide positioning errors can have serious impacts on the definition of vulnerable elements, leading to locally erroneous estimations of landslide risk. Our results suggest that geographically accurate LIMs prepared by adopting the semi-automatic procedure should be preferred to construct accurate multi-temporal or seasonal inventories.

LIMs are also used to determine the statistics of landslide size (area and volume) (Malamud et al., 2004a; Guzzetti et al., 2009), and to investigate correlations between the location and abundance of landslides and the local geological structure (Grelle et al., 2011; Marchesini et al., 2013; Santangelo et al., 2015b). Our results revealed that the geographical accuracy of the location (and hence the shape and size) of the landslides depends on the size of the slope failures (Fig. 7c), with larger positional errors expected for small landslides than for large landslides. The positional errors affecting the small landslides may result in biases in the size of the small failures. This may affect the determination of accurate statistics of landslide areas, and particularly the definition of the most common size for the landslides in a study area i.e., the "rollover" size (Stark and Hovius, 2001; Guzzetti et al., 2002; Malamud et al., 2004b, Stark and Guzzetti, 2009). On the other hand, statistics of the total (cumulated) landslide area and volume, being controlled by the few largest landslides in an inventory (Guzzetti et al., 2008), are not expected to be biased by the positioning errors inevitably present in the inventories, which our results suggest are reduced for very large landslides (Fig. 10).

Guzzetti et al. (2012) and Jackson et al. (2012) have pointed out the need for standards for the production of LIMs. Lack of standards remains a problem that limits the credibility and usefulness of LIMs. The results of our work confirm that standards for transferring the information from the APs to a digital landslide map can (and should) be established. We argue that LIMs produced through API should be accompanied by adequate information (metadata) to explain clearly and unambiguously (among other things) how the landslide information was transferred from the APs to the GIS landslide database. For LIMs produced though a visual transfer of the information (e.g. our map A), the power-law dependency shown in Fig. 10 (or similar relationships) can be used to quantify (and show) the expected positional errors for the landslides shown in the inventory. For maps produced through a robust orthorectification procedure (e.g. our map B), the total RMSE and plots of co-registration accuracy between the orthorectified APs and the reference base map (Fig. 5) should be provided.

Given the clear advantages in terms of the positioning accuracy of the thematic (geomorphological) information in the final map, we expect that the new semi-automatic procedure will be suited also to the production of thematic maps (e.g. land-use maps or morpho-structural maps) based on information obtained from the interpretation of APs.

\section{Conclusions}

Preparing accurate landslide inventory maps (LIMs) is crucial to modern landslide research. However, the production of accurate LIMs is time-consuming, limiting the ability of investigators to cover large areas. Also, the production of LIMs remains a largely manual (craftsmanship) exercise. This introduces subjectivity and errors in the process, and increases the costs for the production of the LIMs.

We have experimented a new procedure for the semiautomatic mapping of landslides that uses robust orthorectification in a GIS environment to transfer accurately and efficiently landslide information drawn by an interpreter on the aerial photographs into a digital landslide database stored in the GIS. The new semi-automatic procedure reduces the time and effort required to prepare a LIM significantly, augmenting the interpreter's efficiency and productivity by a factor of $\sim 2$. The semi-automatic procedure results in the production of more accurate LIMs, compared to landslide maps produced manually.

Systematic application of the new procedure in a $93 \mathrm{~km}^{2}$ area in NE Sicily, Italy, revealed that a common metric used to evaluate the degree of matching (or mismatching) between two LIMs available for the same area (Carrara et al., 1992; Ardizzone et al., 2002) underestimates (severely, in places) the local mismatch between pairs of corresponding landslides in the two inventories. Our results further revealed a dependency of the positional error of a landslide on the size of the landslide, with small landslides characterized by significantly larger errors than the large and very large landslides. The finding has potential consequences for multiple applications of landslide studies.

Finally, our results suggest that standards for transferring the information from the APs to a digital landslide map can (and should) be established, contributing to the definition of much needed standards for the production and use of landslide inventory maps (Guzzetti et al., 2012) and other geomorphological maps obtained through the visual interpretation of aerial photographs. 
Acknowledgements. We thank Mauro Rossi, CNR IRPI, for determining the probability distribution of landslide areas for the two inventories. M. Santangelo, F. Bucci, were partially supported by a grant of the Italian National Department of Civil Protection. F. Fiorucci was supported by a grant of the Umbria Region, under contract POR-FESR 861,2012. This research was conducted during M. Santangelo PhD studies at Dipartimento di Fisica e Geologia, Università degli Studi di Perugia, Piazza dell'Università 1, 06100 Perugia, Italy.

Disclaimer. In this work, use of copyright, brand, trade names, and logos is for descriptive and identification purposes only, and does not imply endorsement from the authors, or their institutions.

Edited by: K.-T. Chang

Reviewed by: P. Bobrowsky and one anonymous referee

\section{References}

Antonini, G., Cardinali, M., Guzzetti, F., Reichenbach, P., and Sorrentino, A.: Carta Inventario dei Fenomeni Franosi della Regione Marche ed aree limitrofe, Publication no. 580, 2 sheets, 2816, 2817, 2836, scale 1:100000, CNR Gruppo Nazionale per la Difesa dalle Catastrofi Idrogeologiche, Rome, 1993.

Antonini, G., Ardizzone, F., Cacciano, M., Cardinali, M., Castellani, M., Galli, M., Guzzetti, F., Reichenbach, P., and Salvati, P.: Rapporto Conclusivo Protocollo d'Intesa fra la Regione dell'Umbria, Direzione Politiche Territoriali Ambiente e Infrastrutture, ed il CNR IRPI di Perugia per l'acquisizione di nuove informazioni sui fenomeni franosi nella regione dell'Umbria, la realizzazione di una nuova carta inventario dei movimenti franosi e dei siti colpiti da dissesto, l'individuazione e la perimetrazione delle aree a rischio da frana di particolare rilevanza, e l'aggiornamento delle stime sull'incidenza dei fenomeni di dissesto sul tessuto insediativo, infrastrutturale e produttivo regionale, Unpublished report, May 2002, 140 pp., 2002a.

Antonini, G., Ardizzone, F., Cardinali, M., Galli, M., Guzzetti, F., and Reichenbach, P.: Surface deposits and landslide inventory map of the area affected by the 1997 Umbria-Mare earthquakes, B. Soc. Geol. Ital., 121, 843-853, 2002 b.

APAT: Servizio Geologico d'Italia, Dipartimento Difesa del Suolo, Carta Geologica d'Italia alla scala 1:50000, Foglio 613 Taormina, S.EL.CA., Firenze, available at: http://www. isprambiente.gov.it/Media/carg/613_TAORMINA/Foglio.html (last access: 30 June 2015), 2008.

Ardizzone, F., Cardinali, M., Carrara, A., Guzzetti, F., and Reichenbach, P.: Impact of mapping errors on the reliability of landslide hazard maps, Nat. Hazards Earth Syst. Sci., 2, 3-14, doi:10.5194/nhess-2-3-2002, 2002.

Ardizzone, F., Cardinali, M., Galli, M., Guzzetti, F., and Reichenbach, P.: Identification and mapping of recent rainfall-induced landslides using elevation data collected by airborne Lidar, Nat. Hazards Earth Syst. Sci., 7, 637-650, doi:10.5194/nhess-7-6372007, 2007.

Ardizzone, F., Basile, G., Cardinali, M., Casagli, N., Del Conte, S., Del Ventisette, C., Fiorucci, F., Garfagnoli, F., Gigli, G., Guzzetti, F., Iovine, G. G. R., Mondini, A. C., Moretti, S., Panebianco, M., Raspini, F., Reichenbach, P., Rossi, M., Tan- teri, L., and Terranova, O. G.: Landslide inventory map for the Briga and the Giampilieri catchments, NE Sicily, Italy, J. Maps, 8, 176-180, doi:10.1080/17445647.2012.694271, 2012.

Ardizzone, F., Fiorucci, F., Santangelo, M., Cardinali, M., Mondini, A. C., Rossi, M., Reichenbach, P., and Guzzetti, F.: Use of very-high resolution stereoscopic satellite images for landslide mapping, in: Landslide Science and Practice, edited by: Margottini, C., Canuti, P., and Sassa, K., Springer, Berlin, Heidelberg, 95-101, 2013.

Bernstein, R.: Image geometry and rectification, in: Manual of Remote Sensing, edited by: Colwell, R. N., American Society of Photogrammetry, Falls Church, VA, 1983.

Borghuis, A. M., Chang, K., and Lee, H. Y.: Comparison between automated and manual mapping of typhoon-triggered landslides from SPOT-5 imagery, Int. J. Remote Sens., 28, 1843-1856, 2007.

Brabb, E. E. and Pampeyan, E. H.: Preliminary map of landslide deposits in San Mateo County, California, US Geological Survey Miscellaneous Field Studies Map, MF-344, US Geological Survey, 1972.

Brabb, E. E., Wieczorek, G. F., and Harp, E. L.: Map showing 1983 landslides in Utah, U.S. Geological Survey Miscellaneous Field Studies Map, MF-1867, US Geological Survey, 1989.

Brunsden, D.: Mass movements; the research frontier and beyond: a geomorphological approach, Geomorphology, 7, 85-128, 1993.

Cardinali, M., Guzzetti, F., and Brabb, E. E.: Preliminary map showing landslide deposits and related features in New Mexico, US Geological Survey Open File Report 90/293, 4 sheets, scale $1: 500$ 000, US Geological Survey, Washington, 1990.

Cardinali, M., Antonini, G., Reichenbach, P., and Guzzetti, F.: Photo geological and landslide inventory map for the Upper Tiber River basin, Publication n. 2116, scale $1: 100$ 000, GNDCI INternal Report, CNR, Gruppo Nazionale per la Difesa dalle Catastrofi Idrogeologiche, Rome, 2001.

Cardinali, M., Reichenbach, P., Guzzetti, F., Ardizzone, F., Antonini, G., Galli, M., Cacciano, M., Castellani, M., and Salvati, P.: A geomorphological approach to the estimation of landslide hazards and risks in Umbria, Central Italy, Nat. Hazards Earth Syst. Sci., 2, 57-72, doi:10.5194/nhess-2-57-2002, 2002.

Carrara, A., Cardinali, M., and Guzzetti, F.: Uncertainty in assessing landslide hazard and risk, ITC Journal, 2, 172-183, 1992.

Cheng, K. S., Wei, C., and Chang, S. C.: Locating landslides using multi-temporal satellite images, Adv. Space Res., 33, 96-301, 2004.

Congalton, R. G.: A review of assessing the accuracy of classifications of remotely sensed data, Remote Sens. Environ., 37, 35-46, 1991.

Cruden, D. M. and Varnes, D. J.: Landslide types and processes, in: Landslides, Investigation and Mitigation, edited by: Turner, A. K. and Schuster, R. L., Transportation Research Board Special Report 247, Washington, D.C., 36-75, 1996.

Delaunay, J.: Carte de France des zones vulnèrables a des glissements, écroulements, affaissements et effrondrements de terrain, 81 SGN 567 GEG, Bureau de Recherches Géologiques et Minières, 23 pp., 1981.

Di Maggio, C., Madonia, G., and Vattano, M.: Deep-seated gravitational slope deformations in western Sicily: controlling factors, triggering mechanisms, and morpho- 
evolutionary models, Geomorphology, 129, 173-189, doi:10.1016/j.geomorph.2013.11.023, 2014.

Duman, T. Y., Çan, T., Emre, Ö., Keçer, M., Doğan, A., Şerafettin, A., and Serap, D.: Landslide inventory of northwestern Anatolia, Turkey, Eng. Geol., 77, 99-114, 2005.

Fiorucci, F., Cardinali, M., Carlà, R., Rossi, M., Mondini, A. C., Santurri, L., Ardizzone, F., and Guzzetti, F.: Seasonal landslides mapping and estimation of landslide mobilization rates using aerial and satellite images, Geomorphology, 129, 59-70, doi:10.1016/j.geomorph.2011.01.013, 2011.

Galli, M., Ardizzone, F., Cardinali, M., Guzzetti, F., and Reichenbach, P.: Comparing landslide inventory maps, Geomorphology, 94, 268-289, doi:10.1016/j.geomorph.2006.09.023, 2008.

Gao, J. and Maroa, J.: Topographic controls on evolution of shallow landslides in pastoral Wairarapa, New Zealand, 1979-2003, Geomorphology, 114, 373-381, doi:10.1016/j.geomorph.2009.08.002, 2010.

Giordan, D., Allasia, P., Manconi, A., Baldo, M., Santangelo, M., Cardinali, M., Corazza, A., Albanese, V., Lollino, G., and Guzzetti, F.: Morphological and kinematic evolution of a large earthflow: the Montaguto landslide, southern Italy, Geomorphology, 187, 61-79, 2013.

GRASS Development Team: Geographic Resources Analysis Support System (GRASS) Software, Version 6.4.0, Open Source Geospatial Foundation, available at: http://grass.osgeo.org (last access: 30 June 2015), 2012.

Grelle, G., Revellino, P., Donnarumma, A., and Guadagno, F. M.: Bedding control on landslides: a methodological approach for computer-aided mapping analysis, Nat. Hazards Earth Syst. Sci., 11, 1395-1409, doi:10.5194/nhess-11-1395-2011, 2011.

Guzzetti, F. and Cardinali, M.: Carta Inventario dei Fenomeni Franosi della Regione dell'Umbria ed aree limitrofe, Publication n. 204, 2 sheets, scale 1:100000, CNR, Gruppo Nazionale per la Difesa dalle Catastrofi Idrogeologiche, Rome, 1989.

Guzzetti, F. and Cardinali, M.: Landslide inventory map of the Umbria region, Central Italy, in: Proceedings ALPS 90 6th International Conference and Field Workshop on Landslides, edited by: Cancelli, A., Milan, Italy, 273-284, 1990.

Guzzetti, F., Malamud, B. D., Turcotte, D. L., and Reichenbach, P.: Power-law correlations of landslide areas in central Italy, Earth Planet. Sc. Lett., 195, 169-183, 2002.

Guzzetti, F., Reichenbach, P., Cardinali, M., Galli, M., and Ardizzone, F.: Probabilistic landslide hazard assessment at the basin scale, Geomorphology, 72, 272-299, doi:10.1016/j.geomorph.2005.06.002, 2005.

Guzzetti, F., Galli, M., Reichenbach, P., Ardizzone, F., and Cardinali, M.: Landslide hazard assessment in the Collazzone area, Umbria, Central Italy, Nat. Hazards Earth Syst. Sci., 6, 115-131, doi:10.5194/nhess-6-115-2006, 2006.

Guzzetti, F., Ardizzone, F., Cardinali, M., Galli, M., and Reichenbach, P.: Distribution of landslides in the Upper Tiber River basin, central Italy, Geomorphology, 96, 105-122, doi:10.1016/j.geomorph.2007.07.015, 2008.

Guzzetti, F., Ardizzone, F., Cardinali, M., Rossi, M., and Valigi, D.: Landslide volumes and landslide mobilization rates in Umbria, central Italy, Earth Planet. Sc. Lett., 279, 222-229, doi:10.1016/j.epsl.2009.01.005, 2009.

Guzzetti, F., Mondini, A. C., Cardinali, M., Fiorucci, F., Santangelo, M., and Chang, K. T.: Landslide inventory maps: new tools for and old problem, Earth-Sci. Rev., 112, 42-66, doi:10.1016/j.earscirev.2012.02.001, 2012.

Haneberg, W. C., Cole, W. F., and Kasali, G.: High-resolution lidarbased landslide hazard mapping and modeling, UCSF Parnassus Campus; San Francisco, USA, B. Eng. Geol. Environ., 68, $263-$ 276, doi:10.1007/s10064-009-0204-3, 2009.

Jackson Jr., L. E., Bobrowsky, P. T., and Bichler, A.: Identification, Maps and Mapping - Canadian Technical Guidelines and Best Practices Related to Landslides: A National Initiative for Loss Reduction, Geological Survey of Canada, Open File 7059, doi:10.4095/292122, 2012.

Lu, P., Stumpf, A., Kerle, N., and Casagli, N.: Object-oriented change detection for landslide rapid mapping, IEEE T. Geosci. Remote, 8, 701-705, 2011.

Malamud, B. D., Turcotte, D. L., Guzzetti, F., and Reichenbach, P.: Landslide inventories and their statistical properties, Earth Surf. Proc. Land., 29, 687-711, 2004a.

Malamud, B. D., Turcotte, D. L., Guzzetti, F., and Reichenbach, P.: Landslides, earthquakes, and erosion, Earth Planet. Sci. Lett., 229, 45-59, doi:10.1016/j.eps1.2004.10.018, 2004b.

Marcelino, E. V., Formaggio, A. R., and Maeda, E. E.: Landslide inventory using image fusion techniques in Brazil, Int. J. Appl. Earth Obs., 11, 181-191, 2009.

Marchesini, I., Santangelo, M., Fiorucci, F., Cardinali, M., Rossi, M., and Guzzetti, F.: A GIS method for obtaining geologic bedding attitude, in: Landslide Science and Practice, edited by: Margottini, C., Canuti, P., and Sassa, K., Springer, Berlin, Heidelberg, 243-247, 2013.

Martha, T. R., Kerle, N., Jetten, V., van Westen, C., and Vinod Kumar, K.: Characterising spectral, spatial and morphometric properties of landslides for semi-automatic detection using objectoriented methods, Geomorphology, 116, 24-36, 2010.

McDonald, H. C. and Grubbs, R. C.: Landsat imagery analysis: an aid for predicting landslide prone areas for highway construction, Vol. 1-b, NASA Earth Resource Survey Sym., Houston, Texas, 769-778, 1975.

Mondini, A. C. and Chang, K.-T.: Combining spectral and geoenvironmental information for probabilistic event landslide mapping, Geomorphology, 213, 183-189, doi:10.1016/j.geomorph.2014.01.007, 2014.

Mondini, A. C., Chang, K.-T., and Yin, H.-Y.: Combining multiple change detection indices for mapping landslides triggered by typhoons, Geomorphology, 134, 440-451, doi:10.1016/j.geomorph.2011.07.021, 2011a.

Mondini, A. C., Guzzetti, F., Reichenbach, P., Rossi, M., Cardinali, M., and Ardizzone, F.: Semi-automatic recognition and mapping of rainfall induced shallow landslides using satellite optical images, Remote Sens. Environ., 115, 1743-1757, doi:10.1016/j.rse.2011.03.006, 2011 b.

Mondini, A. C., Marchesini, I., Rossi, M., Chang, K.-T., Pasquariello, G., and Guzzetti, F.: Bayesian framework for mapping and classifying shallow landslides exploiting remote sensing and topographic data, Geomorphology, 201, 135-147, doi:10.1016/j.geomorph.2013.06.015, 2013.

Mondini, A. C., Viero, A., Cavalli, M., Marchi, L., Herrera, G., and Guzzetti, F.: Comparison of event landslide inventories: the Pogliaschina catchment test case, Italy, Nat. Hazards Earth Syst. Sci., 14, 1749-1759, doi:10.5194/nhess-14-1749-2014, 2014. 
Murillo-García, F. G., Alcántara-Ayala, I., Ardizzone, F., Cardinali, M., Fiourucci, F., and Guzzetti, F.: Satellite stereoscopic pair images of very high resolution: a step forward for the development of landslide inventories, Landslides, 12, 277-291, doi:10.1007/s10346-014-0473-1, 2015.

Nichol, E. J., Shaker, A., and Wong, M. S: Application of highresolution stereo satellite images to detailed landslide hazard assessment, Geomorphology, 76, 68-75, 2006.

Pike, R. J.: The geometric signature: quantifying landslide-terrain types from digital elevation models, Math. Geol., 20, 491-511, doi:10.1007/BF00890333, 1988.

Radbruch-Hall, D. H., Colton, R. B., Davies, W. E., Lucchitta, I., Skipp, B. A., and Varnes, D. J.: Landslide overview map of the conterminous United States, US Geological Survey Professional Paper 1183, US Geological Survey, Washington, 25 pp., 1982.

Razak, K. A., Straatsma, M. W., van Westen, C. J., Malet, J.P., and de Jong, S. M.: Airborne laser scanning of forested landslides characterization: terrain model quality and visualization, Geomorphology, 126, 186-200, doi:10.1016/j.geomorph.2010.11.003, 2011.

Razak, K. A., Santangelo, M., Van Westen, C. J., Straatsma, M. W., and de Jong, S. M.: Generating an optimal DTM from airborne laser scanning data for landslide mapping in a tropical forest environment, Geomorphology, 190, 112-125, 2013.

Reichenbach, P., Guzzetti, F., and Cardinali., M.: Map of sites historically affected by landslides and floods, The AVI Project, 2nd Edn., CNR GNDCI Publication Number 1782, map at $1: 1200000$ scale, CNR, Rome, 1998.

Reichenbach, P., Galli, M., Cardinali, M., Guzzetti, F., and Ardizzone, F.: Geomorphological mapping to assess landslide risk: concepts, methods and applications in the Umbria region 25 of Central Italy, in: Landslide Hazard and Risk, edited by: Glade, T., Anderson, M. G., and Crozier, M. J., John Wiley \& Sons, Ltd., Chippenham, 429-468, 2004.

Rocchini, D., Metz, M., Frigeri, A., Delucchi, L., Marcantonio, M., and Neteler, M.: Robust rectification of aerial photographs in an open source environment, Computers Geosci., 39, 145-151, doi:10.1016/j.cageo.2011.06.002, 2011.

Rosin, P. L. and Hervás, J.: Remote sensing image thresholding methods for determining landslide activity, Int. J. Remote Sens., 26, 1075-1092, 2005.

Rossi, M., Guzzetti, F., Reichenbach, P., Mondini, A. C., and Peruccacci, S.: Optimal landslide susceptibility zonation based on multiple forecasts, Geomorphology, 114, 129-142, doi:10.1016/j.geomorph.2009.06.020, 2009.

Salvati, P., Guzzetti, F., Reichenbach, P., Cardinali, M., and Stark, C. P.: Map of landslides and floods with human consequences in Italy, CNR Gruppo Nazionale per la Difesa dalle Catastrofi Idrogeologiche Publication n. 2822, scale $1: 1200$ 000, CNR, Rome, 2003.

Santangelo, M., Cardinali, M., Rossi, M., Mondini, A. C., and Guzzetti, F.: Remote landslide mapping using a laser rangefinder binocular and GPS, Nat. Hazards Earth Syst. Sci., 10, 25392546, doi:10.5194/nhess-10-2539-2010, 2010.
Santangelo, M., Maresini, I., Bucci, F., Fiorucci, F., Cardinali, M., and Guzzetti, F.: Landslide mapping: improving accuracy and efficiency, in: Proceedings of the 7th EUREGEO Congress, 1215 June 2012, Bologna, 788-789, 2012.

Santangelo, M., Gioia, D., Cardinali, M., Guzzetti, F., and Schiattarella, M.: Interplay between mass movement and fluvial network organization: an example from southern Apennines, Italy, Geomorphology, 188, 54-67, doi:10.1016/j.geomorph.2012.12.008, 2013.

Santangelo, M., Gioia, D., Cardinali, M., Guzzetti, F., and Schiattarella, M.: Landslide inventory map for the upper Sinni River valley, Southern Italy, J. Maps, 11, 444-453, doi:10.1080/17445647.2014.949313, 2015a.

Santangelo, M., Marchesini, I., Cardinali, M., Fiorucci, F., Rossi, M., Bucci, F., and Guzzetti, F.: A method for the assessment of the influence of bedding on landslide abundance and types, Landslides, 12, 295-309, doi:10.1007/s10346-014-0485-x, 2015b.

Sauchyn, D. J. and Trench, N. R.: Landsat applied to landslide mapping, Photogramm. Eng. Rem. S., 44, 735-741, 1978.

Stark, C. P. and Guzzetti, F.: Landslide rupture and the probability distribution of mobilized debris volumes, J. Geophys. Res., 114, F00A02, doi:10.1029/2008JF001008, 2009.

Stark, C. P. and Hovius, N.: The characterization of landslide size distributions, Geophys. Res. Lett., 28, 1091-1094, doi:10.1029/2000GL008527, 2001.

Stumpf, A. and Kerle, N.: Object-oriented mapping of landslides using Random Forest, Remote Sens. Environ., 115, 2564-2577, doi:10.1016/j.rse.2011.05.013, 2011.

Thiery, Y., Malet, J.-P., Sterlacchini, S., Puissant, A., and Maquaire, O.: Landslide susceptibility assessment by bivariate methods at large scales: application to a complex mountainous environment, Geomorphology, 92, 38-59, 2007.

Trigila, A., Iadanza, C., and Spizzichino, D.: Quality assessment of the Italian Landslide Inventory using GIS processing, Landslides, 7, 455-470, doi:10.1007/s10346-010-0213-0, 2010.

Van Den Eeckhaut, M., Poesen, J., Verstraeten, G., Vanacker, V., Moeyersons, J., Nyssen, J., van Beek, L. P. H., and Vandekerckhove, L.: Use of LIDAR-derived images for mapping old landslides under forest, Earth Surf. Proc. Land., 32, 754-769, doi:10.1002/esp.1417, 2007.

Van Den Eeckhaut, M., Kerle, N., Poesen, J., and Hervás, J.: Objectoriented identification of forested landslides with derivatives of single pulse LiDAR data. Geomorphology, 173-174, 30-42, doi:10.1016/j.geomorph.2012.05.024, 2012.

Yang, X. and Chen, L.: Using multi-temporal remote sensor imagery to detect earthquake-triggered landslides, Int. J. Appl. Earth Obs., 12, 487-495, 2010. 